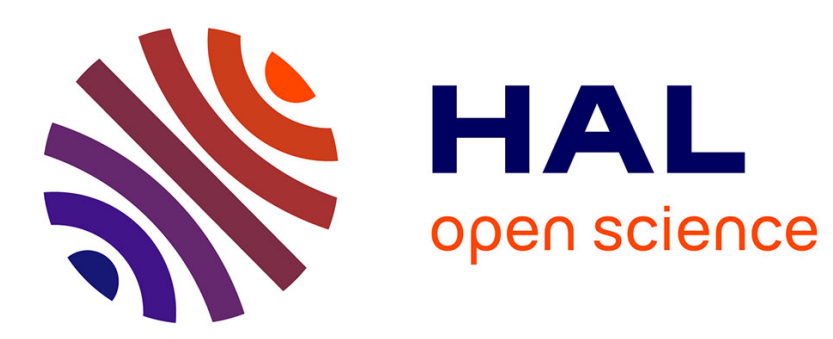

\title{
MICROPLASTICITY AND INTERNAL FRICTION IN PURE IRON
}

\author{
J. San Juan, L. No, Gilbert Fantozzi, C. Esnouf, F. Vanoni
}

\section{To cite this version:}

J. San Juan, L. No, Gilbert Fantozzi, C. Esnouf, F. Vanoni. MICROPLASTICITY AND INTERNAL FRICTION IN PURE IRON. Journal de Physique Colloques, 1981, 42 (C5), pp.C5-43-C5-48. 10.1051/jphyscol:1981505 . jpa-00220961

\section{HAL Id: jpa-00220961 https://hal.science/jpa-00220961}

Submitted on 1 Jan 1981

HAL is a multi-disciplinary open access archive for the deposit and dissemination of scientific research documents, whether they are published or not. The documents may come from teaching and research institutions in France or abroad, or from public or private research centers.
L'archive ouverte pluridisciplinaire HAL, est destinée au dépôt et à la diffusion de documents scientifiques de niveau recherche, publiés ou non, émanant des établissements d'enseignement et de recherche français ou étrangers, des laboratoires publics ou privés. 
JOURNAL DE PHYSIQUE

ColZoque C5, supp Zément au nº, Tome 42, octobre 1981

page $\mathrm{C5}-43$

MICROPLASTICITY AND INTERNAL FRICTION IN PURE IRON

\author{
J. San Juan, L. No, G. Fantozzi, C. Esnouf and F. Vanoni* \\ Groupe d'Etudes de MétalZurgie Physique et Physique des Matériaux, E.R.A. 463 \\ I.N.S.A. Bât. 502, 69621 Vilzeurbanne Cedex, France \\ ${ }^{*}$ C.E.N. Grenoble, D.R.F., 85X, 38041 Grenoble Cedex, France
}

\begin{abstract}
We have studied the microdeformation behaviour of pure iron at Tow temperature ( $4 \mathrm{~K}-250 \mathrm{~K})$. Two thermally activated microdeformation stages are observed : one is associated to the $\alpha$ process observed by internal friction, the other is linked to the $\beta_{\alpha}$ peak. Activation parameters determined for the $\alpha$ component are in good agreement with double-kink formation on non screw dislocations. $\beta_{\alpha}$ component is due to dislocation depinining from an extended atmosphere.
\end{abstract}

1. Introduction.- Generally, the relaxation spectra of plastically b.c.c. metals are composed of three bands of internal friction peaks according to the chambers nomenclature : $\alpha, \beta$ and $\gamma[1,2,3,4]$. Peak $\alpha$ is generally attributed to doublekink nucleation on non screwdislocations, Peak $\beta$ to point defect-dislocation interaction and peak $\gamma$ to double kink generation on screw dislocations. Each relaxation process is characterized by specific activation energies and volumes, which can be determined by internal friction and microdeformation experiments.

In this paper, we study the microdeformation and the internal friction of a pure iron. Many experiments were performed on iron [2]. Generally a peak $\alpha$ is observed around $30 \mathrm{~K}(1 \mathrm{hz})$, with a shoulder $\alpha^{\prime}$ at lower temperatures. The $\alpha$ peak is attributed by Hivert et al. [5] and by Astie et al. [8] to the kink generation on non screw dislocations. Furthermore, for low plastic deformation, a $\beta_{\alpha}$ peak is observed by Ritchie et al. [6] and Dufresne et al. [7], attributed to thermo-mechanical unpinning of dislocation.

2. Experimental procedure.- Experiments were carried out with wires (1mm in diameter, $40 \mathrm{~mm}$ in length) of CENG pure iron, annealed $10 \mathrm{~h}$ at $400^{\circ} \mathrm{C}$ under purified hydrogen. Plastic deformations were performed in torsion at room temperature. Internal friction and microdeformation were measured with an inverted torsional pendulum, with a magnetic field of 200 oe [8]. The internal friction spectra were made at about $0.8 \mathrm{~Hz}$ with an oscillating vibration amplitude $\varepsilon_{\mathrm{m}}=10^{-5}$. We have verified that the static stresses used do not give permanent strains. 


\section{Experimental results}

3.1 Internal friction Fig. 1 presents the internal friction spectra as a function of the plastic deformation amount. After mounting (curve 1), a broad peak is a observed around 130K : this peak is labelled $\beta_{\alpha}$ according to the nomenclature of Ritchie et al. [6]. After $0.5 \%$ deformation (curve 2), this peak growths strongly, shifts towards low temperature (115K) and presents a shoulder between 30 and $50 \mathrm{~K}$ attributed to the $\alpha$ peak. For 2 and $4 \%$ deformation, the $\beta_{\alpha}$ peak situated at $105 \mathrm{~K}$ decreases and the peak $\alpha$ appears at about $30 \mathrm{~K}$ and increases with the deformation amount. As observed by Dufresne et al. [7], the $\beta_{\alpha}$ peak temperature depends strongly on the vibration amplitude.

3.2 Microdeformation Figures 2,3,4 and 5 show the variation of micro deformation versus temperature according to the method used by Esnouf and Fantozzi [9] (the microdeformation plotted $\varepsilon$ is corrected from the shear modulus variation with temperature $\left.\varepsilon=\varepsilon_{\text {real }} \frac{\mu(T)}{\mu_{0}}\right)$. When the static stress $\sigma_{s}$ is applied at $4 K$, an elastic strain $A B$ is observed. Then, during the linear heating, an extra amount of microstrain $B C$ occurs. Subsequently, the specimen is cooled down to $4 K$ (CD) and the static stress is removed : microdeformation recovered during the suppression of the stress is $D E$.

During a subsequent heating without stress, we observe a recovery of the strain (EF).

We have obtained similar results for different values of static stress.

The essential features of fig. 2 to 5 are as follows:

(1) - During the first heating with the static stress $\sigma_{S}$, microdeformation $B C$ occurs in two stages: stage $\alpha$ between 10 and 50K and stage $\beta$ between 70 and 140K. Stage $\alpha$ shifts towards low temperatures and increases strongly with the plastic deformation. The $\beta$ component is lower than the $\alpha$ one and shows only a slight increase with the plastic deformation amount.

(2) - The recovery $D E$ obtained by suppressing the stress at $4 \mathrm{~K}$ is nearly equal to the elastic deformation $A B$.

(3) - During the successive heating without stress (EF), recovery of the strain occurs in two stages $\alpha_{r}$ and $\beta_{r}$. Stage $\alpha_{r}$ takes place at lower temperature than $\alpha$ stage and is more important for deformed specimens. Stage $\beta_{r}$ occurs up to high temperatures and another recovery phenomenon takes place beyond about 200K. Recovery is complete towards $220 \mathrm{~K}$ for non-deformed specimens and towards $250 \mathrm{~K}$ for deformed speciriens.

The derivative curves versus temperature are used to locate the a stage of microdeformation. Fig. 6 a shows the obtained results for the non-deformed specimen : we observe a big shift of the maximum (from $58 \mathrm{~K}$ to $28 \mathrm{~K}$ ) when the bias stress increases. Fig. $6 \mathrm{~b}$ shows the derived curves for a $2 \%$ deformed specinen. Only a low 


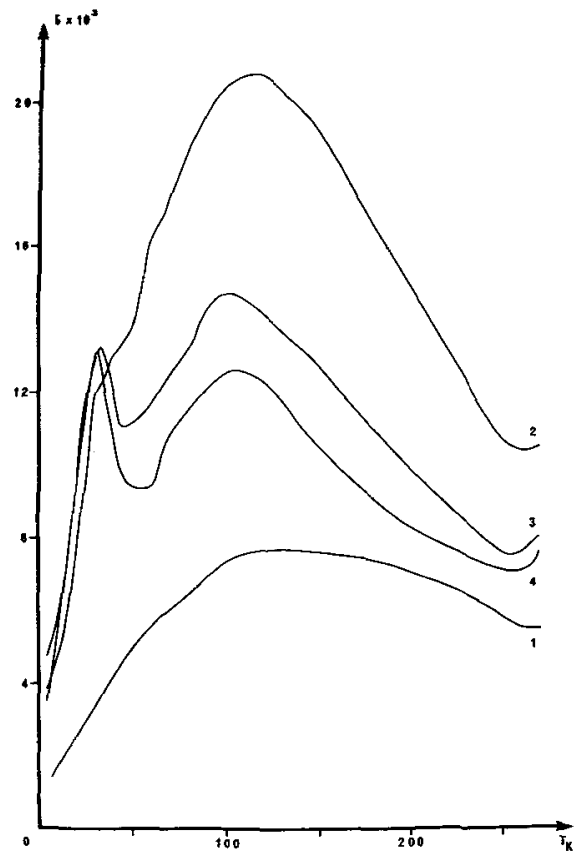

Fig. 1 : Internal friction spectra of Iron $\left(\varepsilon_{m}=10^{-5}\right),(1)$ after mounting; (2) afier $0.5 \%$ plastic deformation at RT; (3) after 2\% deformation;(4) after $4 \%$ deformation. shift of the maximum is observed versus the bias stress. Furthermore, for all the deformed specimens, a substructure of the $\alpha$ stage occurs.

In order to determine the activation volume, we must normalize the microdeformation curves $\varepsilon(T)$ [g]. From the observed shift of the curves versus static stress, we can obtain the activation volume from the following relation :

$$
v=E /\left(\sigma-T \frac{d \sigma}{d T}\right) \text { with } \varepsilon=\text { constant }
$$

The activation energy $E$ for the $\alpha$ peak is about $0.66 \mathrm{eV}$ [5]. The activation volumes measured for different amounts of plastic deformation and for a value of $\sigma_{s}$ equal to about $4.5 \times 10^{-5} \mu$ are given by the following table.

\begin{tabular}{|c|c|c|c|c|}
\hline $\begin{array}{c}\text { plasicic } \\
\text { deformation }\end{array}$ & $\begin{array}{c}\text { non- } \\
\text { deformed }\end{array}$ & $0.5 \%$ & $2 \%$ & $4 \%$ \\
\hline $\mathrm{v} / \mathrm{b}^{3}$ & $60 \pm 10$ & 25 & 12 & $7 \pm 5$ \\
\hline
\end{tabular}

We observe also a decrease of the activation volume when the static stress increases for the non-deformed specimen (from $60 \mathrm{~b}^{3}$ to $20 \mathrm{~b}^{3}$ when $\sigma_{s}$ increases from $2 \times 10^{-5} \mu$ to $7.5 \times 10^{-5} \mu$ ).

\section{4.- Discussion.-}

$\alpha$ process : Microdeformation experiments are interesting because they can show an $\alpha$ component though no $\alpha$ peak is ooserved on the internal friction curve for the non deformed specimen. This result seems to indicate that in the very broad spectrum of $\beta_{\alpha}$ obtained for this specimen, the low temperature range of the spectrum is certainly linked to an intrinsic process $\alpha$.

Stage $\alpha$ observed by microdeformation has the same characteristics than the one observed in f.C.C metals [9]: a stage takes place at higher temperature than the recovery stage $\alpha_{r}$ obtained without stress. The decrease of the activation volume when the plastic deformation increases and the importance of stage $\alpha_{r}$ should indicate that the local internal stress is large (much larger than in f.c.c. metals) and increases with the amount of plastic deformation. This conclusion is similar to the one of Astie' et al. [10] obtained from microdeformation experinents in the $\gamma$ range 
CS -46

JOURNAL DE PHYSIQUE

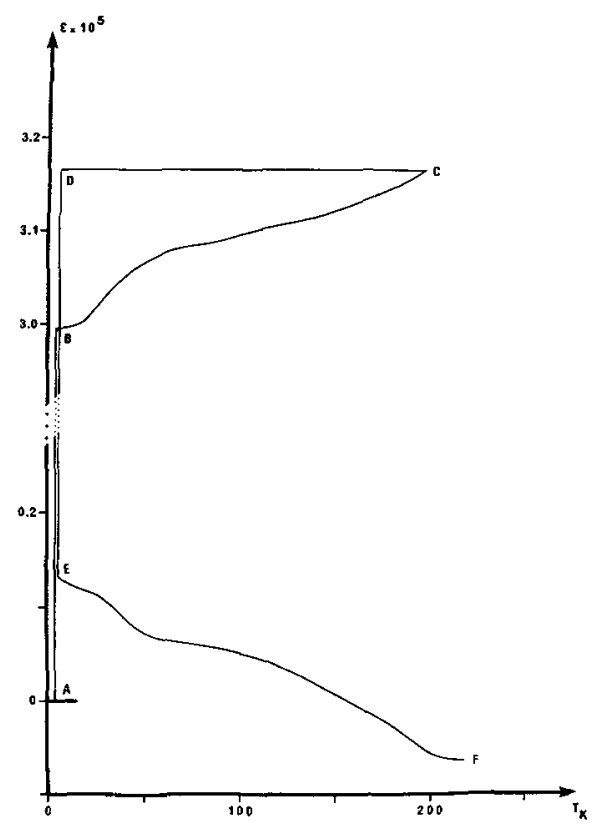

Fig. 2 : Microdeformation in iron without deformation with $\sigma_{\mathrm{s}}=3 \times 10^{-5} \mu_{0}$.

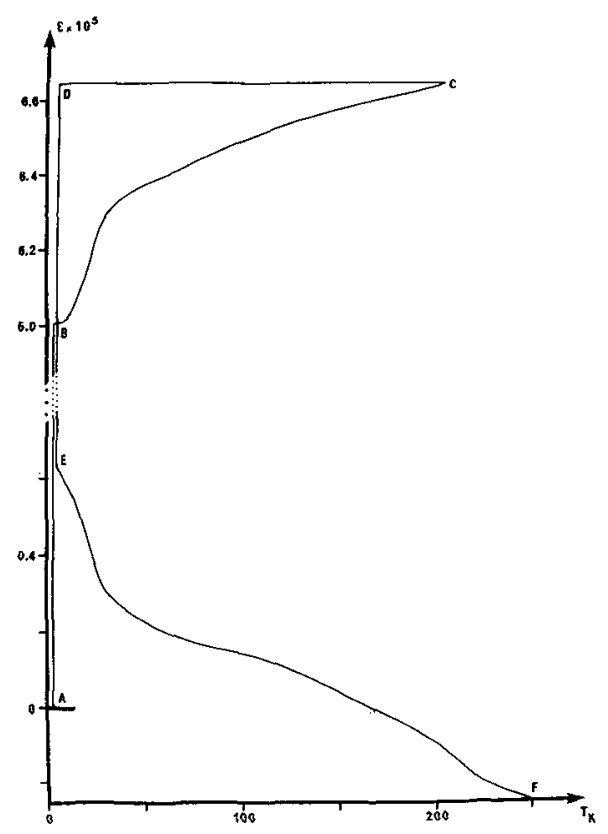

Fig. 4 : Microdeformation in iron after $2 \%$ deformation with $\sigma_{s}=6 \times 10^{-5} \mu_{0}$

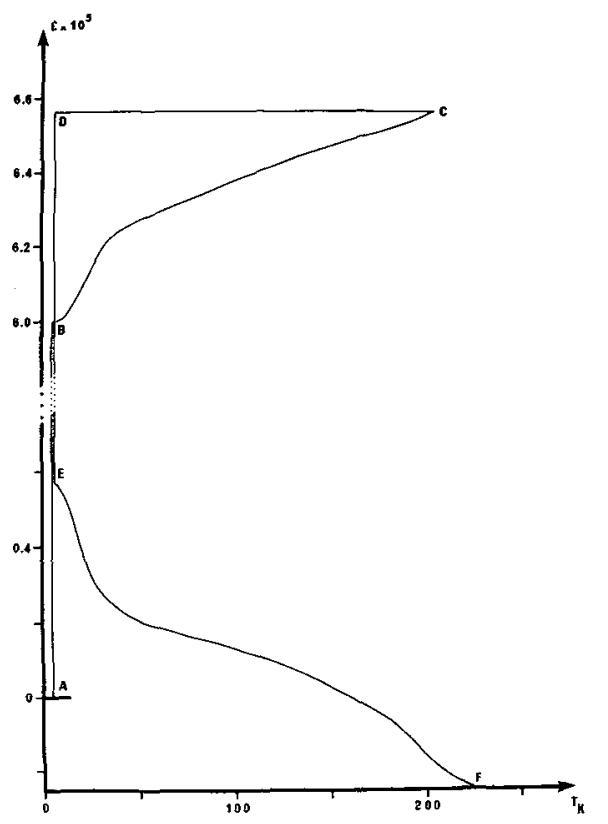

Fig. 3 : Microdeformation in Iron after $0.5 \%$ deformation with $\sigma_{s}=6 \times 10^{-5} \mu_{0}$

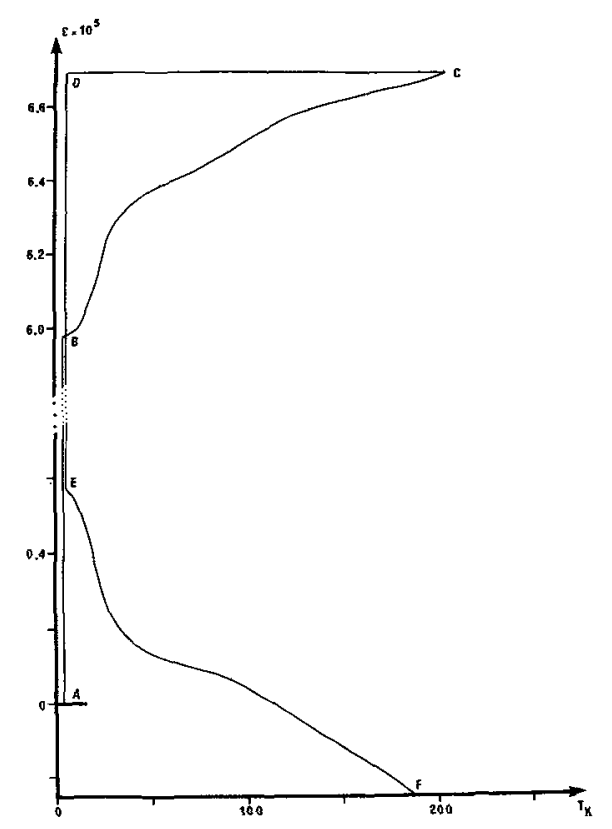

Fig. 5 : Aicrodeformation in Iron after $4 \%$ deformation with $\sigma_{s}=6 \times 10^{-5} \mu_{0}$ 
The features of the $\alpha$ component are in good agreement with the double kink nucleation model on non-screw dislocations $\left(71^{\circ}\right)$. Therefore, these results confirm the given interpretation for the $\alpha$ peak in iron. Furthermore, the microdeformation curves always seem to present an $\alpha^{\prime}$ component at low temperature, which must be precised.

$\beta_{\alpha}$ process : the $\beta_{\alpha}$ peak is generally attributed to the thermomechanical unpinning of non screw dislocations from impurity interstitials $C$ and $N$. The microdeformation experiments show that $\beta_{\alpha}$ is not a simple breakaway process from pinning points situated on the dislocation line. Indeed, in this case, we should observe a microdeformation stage during heating with the static stress and a complete recovery of this deformation during the suppression of $\sigma_{s}$ at $4 \mathrm{~K}$. In fact, no recovery is observed at $4 K$ when the stress is removed (the $A B$ deformation is equal to $D E$ deformation). Therefore, dislocations remain pinned during the suppression of $\sigma_{s}$, pinning points being immobile at consiciered temperature. Thus, we can think that $\beta_{\alpha}$ is due to a dislocation depinning from an extended atmosphere. The microdeformation associated to the $\beta_{\alpha}$ peak occurs in a broad range of temperature as the $\beta_{\alpha}$ peak. It is difficult to observe a shift when the applied stress varies. This situation is not favorable to determine the caracteristics of the $\beta_{\alpha}$ process but it is necessary to use a model of dislocation motion in dilute solid solution as proposed by Schlipf [11] and Ritchie [12].

Acknowledgements.- J. SAN JUAN and $L$. NO on leave of the Physics department of the University of Bilbao gratefully acknowledge the Universidad del Pais Vasco and the Departamento de Educacion del Gobierno Vasco for his financial support.

\section{References}

[1] R.H. Chambers, in Phys. Acoustics (Vol. IIIA), ed. by H.P. Mason, Acad. Press, N.Y. (1966), p. 123.

[2] G. Fantozzi, C. Esnouf, W. Benoit, I. Ritchie, to be published, Progress in ilaterials Science.

[3] H. Schuitz, M. liaul, Y. Rodrian and R. Gren, Proc. 5th. Intern. Symp. on High-Purity Raterials in Science and technology, Vol. III, Dresden (1980), p. 334 .

[4] A. Seeger and C. Wiithrich, Nuovo Cimento, 33 B, 38, 1976.

[5] V. Hivert, P. Groh, W. Frank, I. Ritchie and P. Moser.

Phys. Stat. Sol., (a), 46, 89, 1978.

[6] I.G. Ritchie, J.F. Dufresne and P. Moser, Phys. Stat. Sol., (a), 50, 617, 1978.

[7] Y.F. Dufresne, I.G. Ritchie and P. Moser, ECIFUAS, Manchester (1979), p. 37.

[8] P. Astié, J.P. Peyrade and P. Groh, Scripta Met., 14, 611, 1980.

[9] C. Esnouf and G. Fantozzi, Phil. Mag. A, 42, 63, 1980. 
[10] P. Astié, J.P. Peyrade and P. Groh, this conference.

[11] J. Schlipf, Proc. ICIFUAS-6, Ed. R.R. Hasiguti and is. Mikoshido.

[12] I. Ritchie, this conrerence.

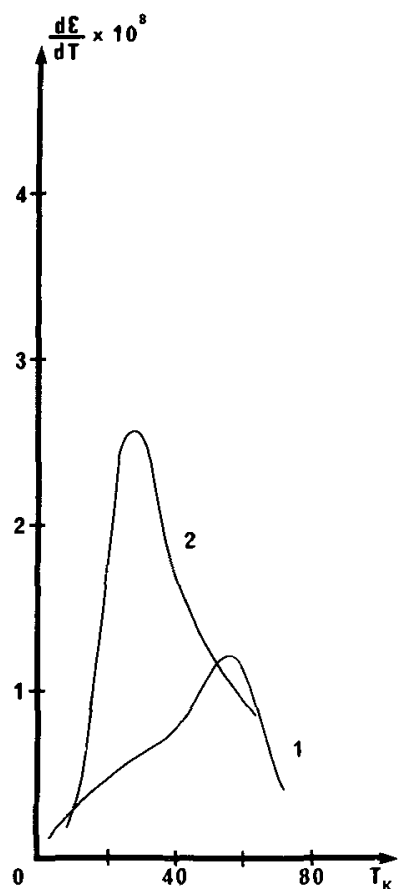

(a)

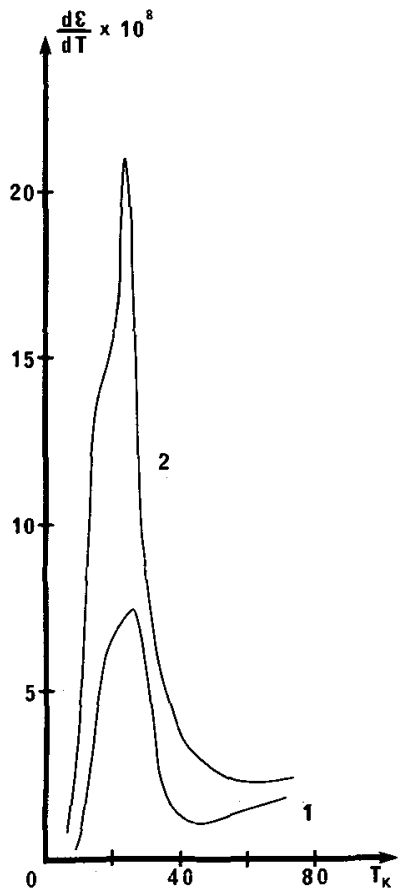

(b)

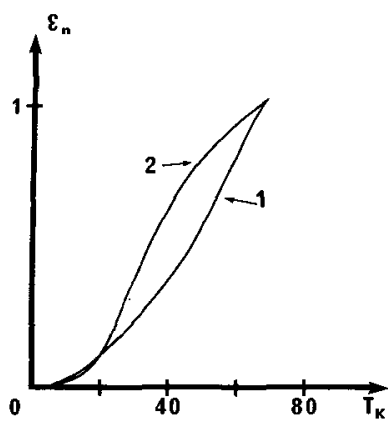

(a)

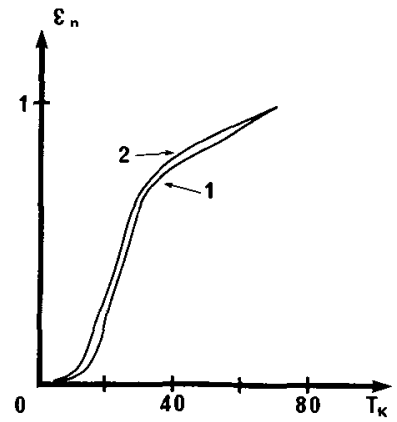

(b)
Fig. 6 : Derived microdeformation curves for iron.
Fig. 7 : Normalized microdeformation curves for iron.
a) without deformation
(1) $\sigma_{S}=10^{-5} \mu_{0}$
(2) $\sigma_{s}=3 \times 10^{-5} \mu_{0}$
b) after $2 \%$ deformation
(1) $\sigma_{s}=3 \times 10^{-5} \mu_{0}$
(2) $\sigma_{s}=6 \times 10^{-5} \mu_{0}$ 